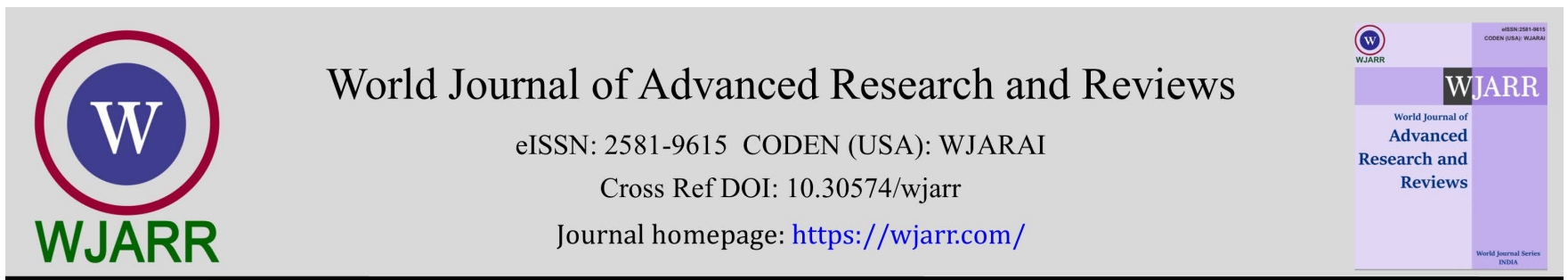

(RESEARCH ARTiClE)

\title{
Socio-demographic factors influencing the level of drug abuse among undergraduates in tertiary institutions in Ebonyi State
}

\author{
Jude N Nwafor 1, Lois N Omaka-Amari 2, Raphael E Ochiaka 3, Eunice N Afoke ${ }^{2}$ Christian O Aleke 2,* and \\ Emeka M Osman ${ }^{2}$ \\ ${ }^{1}$ Department of Physical and Health Education, Ebonyi State University College of Education Ikwo, Nigeria. \\ 2 Department of Human Kinetics and Health Education, Faculty of Education, Ebonyi State University, Abakaliki, Ebonyi \\ State, Nigeria. \\ ${ }^{3}$ Department of Human Kinetics and Health Education, Enugu State University of Science and Technology, Enugu, Nigeria.
}

World Journal of Advanced Research and Reviews, 2021, 12(01), 378-386

Publication history: Received on 28 August 2021; revised on 21 October 2021; accepted on 23 October 2021

Article DOI: https://doi.org/10.30574/wjarr.2021.12.1.0460

\begin{abstract}
This study examined the demographic factors influencing the level of drug abuse among undergraduates of Ebonyi State University. To achieve this, three objectives and corresponding research questions were posed and three hypotheses were formulated and tested at. 05 level of significance. The study design was a descriptive cross-sectional survey. A sample of 943 students was drawn from a population of 18859 students. The instrument for data collection was a threeitem questionnaire titled: Level of Drug Abuse Survey questionnaire (LDASQ) with a reliability coefficient of 0.93. Data were analyzed using Frequency, Percentage and chi-square statistic. The results of the study showed among others, that more males (56.7\%) than females (35.2\%) abused drugs. There was significant association between student gender and level of drug abuse among university students in Ebonyi state. It was recommended among others that the Ministry of Education (Federal and State) must as a matter of urgency add to their curricular drug education for both the primary and secondary schools to enable students understand the adverse effect of drug abuse and as well develop attitude that will help them resist the temptation to abuse drugs even as they enter into high institutions.
\end{abstract}

Keywords: Demographic factors; Drug abuse; Undergraduates; Ebonyi State

\section{Introduction}

Drug abuse is a global challenge with detrimental effects on health, wealth and security of all nations [1]. There is growing concern worldwide over the growing number of youths involved in drug abuse [2]. A study revealed that 4.8\% of the global population consume illicit drugs [3]. The worrying fact is that those hooked are mostly the youth [3]. In Nigeria the problem of drug abuse is very high, it is further compounded by the absence of up-to-date records and the gross absence of infrastructural facility to handle the treatment of cases of drug abuse,[4]. Nigerian drug statistics based on the six geo- political zones of the country showed that the North West Zone ranked highest in drug addiction as it accounted for 755 arrested drug abusers or $47.45 \%$ of the total drug addiction in the country within the period. South West Zone came second with 347 arrested representing 27.32\%The South East Zone placed third with 263 arrested representing $23.5 \%$ of the total drug addiction in the country within the period [4]. There is no doubt that those yet to be identified or arrested are twice more than the number already identified.

Drug can be viewed as a substance that could bring about a change in the body physiology through its action [5]. It is also considered as a substance that modifies awareness, cognition, disposition, manners and general body functions [6]. It

\footnotetext{
${ }^{*}$ Corresponding author: Christian O Aleke

Department of Human Kinetics and Health Education, Faculty of Eduucation, Ebonyi State University, Abakaliki, Ebonyi State, Nigeria. Copyright (C) 2021 Author(s) retain the copyright of this article. This article is published under the terms of the Creative Commons Attribution Liscense 4.0.
} 
is also a chemical substance that alters the function of one or more body organs or the course of a disease. Drugs include prescribed medicines, over the counter remedies and substances such as alcohol, tobacco and drugs that are used for none medical purposes [7]. National Agency for Food Drug Administration and Control, explains the term drug abuse as undue and continual self-administration of a drug without regard to the medically or culturally accepted pattern [4]. Other studies also agree that drug abuse is the use of drug for the function it is not meant, prescribed or recommended $[7,8]$. It is a destructive pattern of using a substance that leads to significant problem or misery. For the purpose of this study, drugs are chemical substances that alter the function of one or more body organs or the process of a disease. They include prescribed medicines, over the counter remedies and substances such as alcohol, tobacco, and drugs of abuse that are used for no medical purposes. Drug abuse on the other hand, will be seen as the use of drug(s) for the function it is not meant, prescribed or recommended. Examples of these substances include prescribed medicines, alcohol, tobacco, cocaine, heroin, Valium 5, amphetamines, tramadol, and codeine among others. Studies have identified some socio- demographic variables that are related to attitudinal disposition towards drug abuse by university students to include gender, and parental drug use and peer pressure [9]. These variables will be investigated to determine how they relate to level of drug abuse among university students of Ebonyi State.

Evidence from research indicates that clear differences exist between women and men in their use of drugs. First women consume less alcohol than men when they drink, secondly, women drink alcohol less frequently than men and thirdly, women use illicit drugs far less than men and hence develop drug related problem less than men [10,11]. Studies also reported a greater occurrence of illicit substance use among males than among females [12, 13]. Both surveys have consistently documented this pattern over the years. NHSDA survey, further reported a higher rate of illicit substance use (any illicit drug) among men than women, $8.5 \%$ vs. $4.5 \%$, nearly double. Men report higher rates of cocaine use 0.9 percent versus $0.5 \%$, alcohol use (58\% vs. $45 \%$ ), binge drinking ( $23 \%$ vs. 8\%), and heavy drinking (8.7\% vs. $2.1 \%$ ) [12]. The University of Michigan compiled yearly data on the substance use of 8th, 10th, and 12th graders, college students, and young adults in the MTF study [14]. They maintained that drug use is not equally distributed by gender. Males are more likely to use most illicit drugs. And they report using such drugs earlier and longer than females. Males also use all illicit drugs at a higher frequency and in larger amounts than females.

A number of school and college surveys in Nigeria that alcohol use is the most common among students, with many drinking students having had their first drink in family settings [15]. Study also posited that parental attitudes towards alcohol and drug use are associated closely with young children's attitude towards alcohol and drug abuse [16]. Many studies have singled out the family as the most significant determinant of substance abuse by the youth at the intrapersonal level. It is observed that exposure to alcohol in the family cause risky behaviors such as rebelliousness and having friends who drink [17]. In addition, literature shows that youths that have parents who drink heavily, and/or are tolerant of alcohol use, as well as having close acquaintances who drink, places youths at risk for heavy drinking. In other words, role modeling plays a significant part in the substance abuse space. Youths tend to imitate the behaviours of their parents, guardians or other influential people and quantitative and qualitative evidence suggests that those with adequate role models are less likely to indulge in substance abuse $[18,19]$. On the other hand, a nurturing home environment, encompassing family supervision and monitoring, together with open communication lines between parents and children, has been empirically determined to be strongly associated with low substance abuse [20].

Peer pressure is the direct encouragement from one's age group to engage in activities that they may or may not want to engage in. Peers act as an influential model by introducing, providing or pressuring risky activities like drug use to other peers $[21,22]$. By modeling these behaviours to peers, university students are viewing drug abuse as a positive and socially acceptable experience [22]. Empirical studies indicate that peer pressure is one of the most significant and most consistent predictors of substance use among youth $[23,24]$. Peers encourage their uninitiated peers to use drugs, and more often drug or alcohol use is celebrated with those taking illegal substances held in high regard. Youth will then want to be accepted by their peers in these substance abuse networks at all costs. Peer pressure is rampant in youth gang networks and other marginalized groups such as street children [25]. Evidence also indicates that youth prefer to discuss issues with their peers more than they would with their family members, teachers, or medical doctors [26]. They value opinions or support of their peers more than any other social structure at their disposal [26]. The pressure to be recognized and accepted by peers and gain meaningful participation inadvertently increases vulnerability of the youth [27].

In Ebonyi State where the present study was carried out, the cultural practices of the area such as marriages, burial ceremonies, church weddings, house warming, family meetings, club and community meetings and so on, expose the people to the use of such psychoactive substances as alcohol, tobacco and cola nuts. During marriage ceremonies for example, tobacco and alcohol are compulsory ingredients and elderly family members are seen by the young ones drinking various forms of alcohol, smoking, snuffing or chewing tobacco and eating cola nuts. This forms the basis where the young in the area begin to try it out and go extra miles by trying other forms of illicit drugs like Indian hemp, cocaine, 
heroin metacarphine, tramadol and the likes. A report showed that the prevalence of current use of psychoactive substance in Ebonyi State is more than 50\% [28]. The prevalence rate of drug abuse in Abakaliki, the state capital stood at $49.9 \%$ with alcohol and Indian hemp being the most commonly abused substance especially among youths [29].

Over the years, cases of rape of defenseless female students, armed robbery, violent attack on lectures, cult clashes leading to lose of lives and so on, were rampant among youths in Ebonyi State. These social vices are possible off springs of drug abuse. In view of the place of the youth in national development, coupled with the believe that the school is the factory where the society is produced, it is necessary to investigate the basis of drug abuse prevalent in the state with the aim of putting the problem in check. Of all the studies conducted in the area of drug abuse in Ebonyi State, none was done in the area of demographic factors influencing drug abuse among university students. It is the belief of the researcher that a careful investigation of the variables of this model of health behaviour, will better generate a suitable intervention that will address the problems of drug abuse in the state adequately hence the locus of the present study.

In order to achieve the objectives of the study the following research questions were formulated to guide the study.

- What is the level of drug abuse among university students in Ebonyi State by gender?

- What is the level of drug abuse among university students in Ebonyi state in relation to their parental use of $\operatorname{drug}(\mathrm{s})$ ?

- What is the level of drug abuse among university students in Ebonyi State by peer use of $\operatorname{drug}(\mathrm{s})$ ?

\subsection{Hypotheses}

The study was guided by the following hypotheses that was tested at .05 level of significance

- There is no significant association between student gender and level of drug abuse among university students in Ebonyi State

- There is no significant association between Parental drug abuse and level of drug abuse among university students in Ebonyi State.

- There is no significant association between peer drug abuse and level of drug abuse among university students in Ebonyi State.

\section{Material and methods}

The descriptive survey research design was conducted from April 2019 to February 2020 among undergraduates of the two public universities in Ebonyi State. The population for this study consisted of all the female undergraduates from the two public universities in Ebonyi State. Based on the existing Data from the registrar's office 2019/2020 academic years, the total population of female students in the State universities is 18859.

\subsection{Sample Size}

A sample of 943 undergraduates were drawn for the study. This signified five per cent of the population. Five per cent chosen was considered adequate as it conformed to the rule of the thumbs as stated by Nwana, that when a population under study is in a few hundreds, the sample size should be $40-50$ per cent, if it is in many hundreds, 20 per cent of the population should be used, where the population is in the few thousands, 10 percent will be representative of the population, but when in several thousands, 2 - 5 per cent of the population should be considered [30]. However, the population of the present study was in several thousands (18859), hence five per cent of the population was used.

\subsection{Sample Technique}

The Multi-stage sampling procedure was adopted in selecting the respondents for the study. In the first stage, two (2) public universities were selected from all the tertiary institutions in Ebonyi State, using simple random sampling technique of balloting with replacement. The second stage involved the use of purposive sampling to draw 472 undergraduates from each of the universities selected for the sample. At the end of the sampling, 943 undergraduates were drawn for the study.

\subsection{Inclusions and Exclusion Criteria}

The two universities in Ebonyi State were included in the study and only the students present during the time of data collection and willing to consent were included in the study. Other tertiary institution in the State were excluded, also, students who were absent, sick or refused to consent were excluded from the study. 


\subsection{Instrument for Data Collection}

The instrument for data collection was a three-item questionnaire titled: Level of Drug Abuse Survey questionnaire (LDASQ). The instrument was validated by experts in the Department of Human Kinetics and Health Education and Measurement and Evaluation of Science Education Faculty of Education, Ebonyi State University Abakaliki with a reliability Co-efficient of 0.93 .

\subsection{Statistical Analysis}

All statistical analysis was done using the Statistical Package for Social Science (SPSS) software batch system. Data was analyzed using Frequency, percentage and Chi-square statistic. The level of significance was set at $P<0.05$.

\section{Results}

Table 1 shows the level of drug abuse among university students of Ebonyi State by gender. More males than females indicated higher level of drug abuse. This was shown by $56.7 \%$ of males who abuse drugs at high level while $43.2 \%$ of females abuse drugs at low level. The females indicated $48.8 \%$ low level of drug abuse while the males showed $51.2 \%$ high level of drug abuse. This is a clear indication that the male students abuse drugs more than the female students.

Table 2 shows the level of drug abuse among university students of Ebonyi State by parental drug use status. Students whose parents use drugs indicated $62.6 \%$ high level of drug abuse and $37.4 \%$ low level of drug abuse while students whose parents are non-drug users showed $67.0 \%$ high level of drug abuse and 32.9\% low level of drug abuse. Cumulatively 577 respondents representing $70.4 \%$ of the total population had parents who use drugs in one way or the other.

Table 1 Frequency and Percentage Distribution of Level of Drug Abuse among University Students of Ebonyi State by Gender

\begin{tabular}{|l|c|c|c|}
\hline Gender & Low level & High level & Total \\
\hline Male & $256(48.85 \%)$ & $168(56.76 \%)$ & $424(51.71 \%)$ \\
\hline Female & $268(51.15 \%)$ & $128(43.24 \%)$ & $396(48.29 \%)$ \\
\hline Total & $524(100 \%)$ & $296(100)$ & $820(100)$ \\
\hline
\end{tabular}

Table 2 Frequency and Percentage Distribution of Level of Drug Abuse by University Students of Ebonyi State in Relation to their Parent's use of Drug

\begin{tabular}{|l|l|l|l|}
\hline Parental use of drug & Low level & High level & Total \\
\hline Users & $361(62.6 \%)$ & $216(37.4 \%)$ & $577(70.4 \%)$ \\
\hline Non Users & $163(67.0 \%)$ & $80(33.9 \%)$ & $243(29.6 \%)$ \\
\hline Total & $524(63.9 \%)$ & $296(36.1 \%)$ & $820(100 \%)$ \\
\hline
\end{tabular}

Table 3 Frequency and Percentage Distribution of Level of Drug Abuse Among University Students in Ebonyi State by Peer's use of drugs Status

\begin{tabular}{|l|c|c|l|}
\hline Peer Drug Use & Low Level & High level & Total \\
\hline Peer drug users & $335(63.00 \%)$ & $188(37.00 \%)$ & $524(100 \%)$ \\
\hline Peer non drug users & $189(63.6 \%)$ & $108(36.3 \%)$ & $296(100 \%)$ \\
\hline Total & $524(63.90 \%)$ & $296(36.10 \%)$ & $820(100)$ \\
\hline
\end{tabular}


Table 3 shows the level of drug abuse among university students of Ebonyi State by peer drug use. Students whose peers, abuse drugs at $63.00 \%$ high level and $37.00 \%$ low level while students whose peers are non-users of drugs, abused drugs at $63.6 \%$ high level and $36.3 \%$ low level. This indicates that students whose peers use drugs, abuse drugs more than those whose peers are non-users of drugs.

\subsection{Hypothesis 1}

Table 4 Summary of Chi-Square Analysis of Association between Gender of Students and Level of Drug Abuse among University Students in Ebonyi State

\begin{tabular}{|l|l|l|l|}
\hline Gender & Low Level & High level & Total \\
\hline Male & 256(270.0) & 168(153.1) & $424(424.0)$ \\
\hline Female & $268(253.1)$ & $128(142.9)$ & $396(396.0)$ \\
\hline Total & $524(524.0)$ & $296(296.0)$ & $820(820.0)$ \\
\hline \multicolumn{4}{|c}{$\chi^{2} 4.72, p=0.030$, Decision, Significant }
\end{tabular}

Table 1 shows that the cal $\chi^{2}=4.72$ and the $p=0.030$ is lower than 0.05 . Therefore, the hypothesis of no significant association between gender and level of drug abuse among University Students in Ebonyi State is therefore rejected

\subsection{Hypothesis 2}

Table 5 Chi-Square Summary of Analysis of Association between Parental Drug Use and level of Drug Abuse by University Students in Ebonyi State

\begin{tabular}{|l|c|c|l|}
\hline Parental Drug Use & Low Level & High level & Total \\
\hline Users & $361(368.7)$ & $216(208.3)$ & $577(577.0)$ \\
\hline Non users & $163(155.3)$ & $80(87.7)$ & $243(243.0)$ \\
\hline Total & $524(524.0)$ & $296(296.0)$ & $820(820.0)$ \\
\hline \multicolumn{4}{|c|}{$\chi^{2}=1.5099, \mathrm{p}=0.219$, Decision, Not significant } \\
\hline
\end{tabular}

Table 2 shows that the cal $\chi^{2}=1.509$ and the $p=0.219$ was greater than 0.05 . Therefore, the hypothesis of no significant association between parental drug use and level of drug abuse among university students in Ebonyi State was upheld.

\subsection{Hypothesis 3}

Table 6 Summary of chi-square analysis of association between peer Drug Abuse and Level of drug abuse among University Students in Ebonyi state

\begin{tabular}{|l|l|l|l|}
\hline Peer Drug Use & Low Level & High level & Total \\
\hline Peer drug Users & $335(334.2)$ & $188(188.8)$ & 523(523.0) \\
\hline Peer non users & $189(189.8)$ & $108(107.2)$ & $297(243.0)$ \\
\hline Total & 524(524.0) & 296(296.0) & 820(820.0) \\
\hline
\end{tabular}

Table 3 shows that the cal $\mathrm{x} 2=0.014$ and the $\mathrm{p}=0.09$ was greater than 0.05 . Therefore, the hypothesis of no significant association between peer drug use and level of drug abuse among university students in Ebonyi State was up held.

\section{Discussions}

Findings in Table 1 revealed that more males than females abuse drugs among university students in Ebonyi state. This finding is expected and interesting because it would be a surprise to find the contrary. It is also widely supported by several studies who revealed males abuse drugs more than females [31-34]. However, this finding is at variance with the study who reported that female adolescents who live in urban areas abuse drugs more than males who live in rural 
areas [35]. This finding is also supported by study who revealed that there was no significant difference between the level of drug abuse among males and female students in his study [36].

Results in Table 1 hypothesis 1 showed the summary of chi-square analysis of association between gender of students and level of drug abuse among university students in Ebonyi state. The result showed that the $\mathrm{x} 2$ value of 4.72, $\mathrm{p}=0.030$ is not significant therefore indicating no significant association between gender of students and levels of drug abuse among university students in Ebonyi State was rejected. This result was expected going by the findings of other studies who revealed that clear variations exist between women and men in their use of drugs [10,11]. First women consume less alcohol at a sitting, second, women drink alcohol less often than men and third, women use illicit drugs far less than men and hence develop drug related predicaments less than men. This finding is supported by the study conducted in Nairobi Kenya who reported that males abuse drugs more than females [31]. However, this finding failed to agree with the findings of other study who observed that there was no statistically significant difference between the levels of drug abuse between males and females in his study [36]. The implication of this finding is that both males and females abuse drugs and that the difference in the level of consumption between males and females may depend on the environment of the individual. However, one of the tasks of this study is how to ensure that this does not continue going by its health implications and the need to develop a society of high moral value.

Findings in Table 3 showed that students whose parents use drugs have higher level of drug abuse than those whose parents do not use drugs among university students in Ebonyi state. This was shown by 577 respondents representing $70.4 \%$ of the total population while 243 respondents representing $29.6 \%$ indicated that their parents do not use drugs. This finding explains to some extent why there is high level of drug abuse among university students in Ebonyi State. Broody, Kata and Arials, revealed that parental attitudes towards alcohol and drug use are associated closely with young children's attitude towards alcohol and drug use [16]. This finding is supported by the study who revealed that parental drug use was associated with drug abuse among adolescents and young adults [37]. Although the propensity of use of psychoactive substance by youths has become a global emergency that requires desperate measures to curtail. According to Chukwujekwu, youths known to have parents who abuse drugs are known to show extreme level of drug abuse [38]. The implications of this finding is that whatever children learn from their parents, they hold on to it as good and as such parents should be taught to always show a very good example to members of their family so that their children can be good ambassadors of their family wherever they find themselves. This could be one of the reasons why Bronfenbrenner emphasized the interpersonal level of the socio-ecological theory of health behaviour [39].

Results in Table 4 hypothesis 1 show that there was no significant association between parental drug use and level of drug abuse among university students in Ebonyi State ( $\mathrm{x} 2-19.77, \mathrm{p}=0.001)$. This finding is a surprise because according to Broody, Katx and Arials, parental attitudes towards alcohol and drug use are closely associated with young children's attitude towards drug use [16]. This was also supported by the findings of Branstetter, Sabina and Furman, who reported, that parental drug use was associated with increased drug abuse among adolescents and young adults [37]. In further support to the above, the study by Chukwujekwu found that youths whose parents use drugs are known to show extreme level of drug abuse [38]. This is expected because any form of life style copied at the family level will definitively make a significant impact on the future life of the child and drug use is not an exception.

Results in Table 5 showed a summary of chi-square analysis of association between peer drug use and level of drug abuse among university students in Ebonyi state. The results showed that there was no significant association between student's peer drug use and level of drug abuse among university students in Ebonyi State ( $\mathrm{x} 20.014, \mathrm{p}=0.90)$. Although this finding is as astonishing as it is a surprise, it is supported by the findings who reported that peer group influence varies by individual characteristics including genetics and competency skills [40]. However, this finding is at variance with many research findings on adolescent and young adults peer pressure and drug abuse [41-45]. The implication of this finding is that something can still be done to reduce peer pressure among adolescents and young adults especially in the area of drug abuse.

\section{Conclusion}

Based on the findings and discussions of the study, the following conclusions were reached. More males than females abuse drugs among university students in Ebonyi state. There was significant association between student gender and level of drug abuse among university students in Ebonyi state. Level of drug abuse was higher among students whose Parents use drug than those whose parents are non-drug users but this was not statistically significant. Student whose peers use drugs abuse drugs more than students whose peers do not use drugs. There was no significant association between students peer drug use and level of drug abuse among University students in Ebonyi state. 


\section{Recommendations}

On the basis of the findings of the study, the following recommendations were made:

- Drug education should start at the secondary school level so that students can develop attitude towards drug abuse that will enable them resist the temptation to abuse drugs at the University level.

- The ministry of Education should ensure that all secondary schools and Universities in Nigeria put in place a functional drug policy that will check drug abuse in our public and private institutions.

\section{Compliance with ethical standards}

\section{Acknowledgments}

The authors appreciated all the corrections, suggestions and recommendations by the experts. Also wish to thank the contributions of undergraduates in tertiary institutions in Ebonyi State who completed the questionnaires of this research.

\section{Disclosure of conflict of interest}

The authors declare no conflict of interest.

\section{Authors' contributions}

J.N.N, C.O.A, and LNO., conceived and commissioned the study. J.N.N, performed the literature search and screened for the selected studies, extracted the data and wrote the first draft of the manuscript. ENA, REO, EMO, C.O.A, and LNO supervised all aspects of the study. All the authors have read and agreed to the final manuscript.

\section{Statement of informed consent}

Informed consent was obtained from all individual participants included in the study.

\section{References}

[1] United Nation Office on Drugs and Crime. World Drugs Report, Oxford University Press. 2010.

[2] World drug report. United Nation Office on Drugs and Crime Drugs statistic. 2015; 2(2).

[3] United Nations Office on Drugs and Crime. World Drug Report. Https://www.unodc.org/doc/wdr. United Nations Office on Drugs and Crimes. World Drug Report. 2016; Austria. No.: ISBN 978-92-1-148262-1: 272.

[4] National Drug Law Enforcement Agency (NDLEA) Annual Report. 2012.

[5] Nnachi RO. Advanced psychology of learning and scientific enquiries, Enugu: J. J. Classic Publisher Ltd. 2007.

[6] Okoye NN. The adolescents and hard drugs: A psychological concern in R.U.N. 2001.

[7] British Medical Dictionary. Dorling Kindersley limited, 80 strand London WC2R ORL Penguin Company. 2013.

[8] Medicienet, Drug Abuse and Addiction, Causes, effects, prevention. 2011.

[9] Abdu-Raheem B0. Sociological Factors To Drug Abuse And The Effects On Secondary School Students Academic Performance In Ekiti And Ondo States, Nigeria. Contemporary Issues in Education Research (CIER). 2013; 6(2): 233-240.

[10] Fillmore M. Polydrug Abusers Display Impaired Discrimination-Reversal Training Learning in a Model of Behavioral Control." Journal of Psychopharmacology. 2010; (20): 24-32.

[11] Greenfield B, Venner K. Review of substance use disorder treatment research in Indian Country: Future directions to strive toward health equity. The American Journal of Drug and Alcohol Abuse. 2012; 38(5): 483-492.

[12] National Household Survey on Drug Abuse, (ICPSR 6128). 2015; 11-23.

[13] Monitoring the Future on National survey results On drug use. 2016. Overview the. Sponsored by The National Institute on Drug Abuse at The National. 
[14] Malley PM, Bachman JG, Johnston LD, Schulenberg JE. Monitoring the Future National Results on Adolescent Drug Use. Bethesda, MD: National Institute on Drug Abuse. 2021.

[15] Chikere EIC, Mayowa MO. Prevalence and perceived health effect of alcohol use among male undergraduate students in Owerri, south-East Nigeria: A descriptive cross-sectional study: BMC Public Health. 2011.

[16] Brook S, Morojele NK, Pahl K, Brook DW. Predictors of drug use among South African adolescents. Journal of Adolescent Health. 2006; 38(1): 26-34.

[17] Pretorius L. Women's discourses about secretive alcohol dependence and experiences of accessing treatment. Unpublished dissertation presented for the degree of Doctor of Philosophy in the Department of Psychology at the University of Stellenbosch. 2010.

[18] Morojele, and L Ramsoomar, Addressing adolescent alcohol use in South Africa. South Africa Medicine Journal. 2006; 106(6): 551-553.

[19] Ghuman S, Meyer-Weitz A, Knight S. Prevalence patterns and predictors of alcohol use and abuse among secondary school students in Southern KwaZulu-Natal, South Africa: Demographic factors and the influence of parents and peers. South African Family Practice. 2012; 54(2): 535-544.

[20] Meghdadpour S, Curtis S, Pettifor A, MacPhail C. Factors associated with substance use among orphaned and nonorphaned youth in South Africa. Journal of Adolescence. 2012; 35(5): 1329-1340.

[21] Kinard B, Webster C. The effects of advertising, social influences, and self-efficacy on adolescence tobacco use and alcohol consumption. The Journal of Consumer Affairs. 2010; 44(1), 24-43.

[22] Collins SE, Clifasefi SL, Logan DE, Samples L, Somers J, Marlatt GA. Ch. 1: Harm reduction: Current status, historical highlights and basic principles. In G.A. Marlatt, K. Witkiewitz, \& M.E. Larimer (Eds.), Harm reduction: Pragmatic strategies for managing high-risk behaviors (2nd ed.). New York. 2011.

[23] Brook S, Morojele NK, Pahl K, Brook DW. Predictors of drug use among South African adolescents. Journal of Adolescent Health. 2006; 38(1): 26-34.

[24] Van Zyl AE. Drug Use amongst South African Youth: Reasons and Solutions. Mediterranean Journal of Social Science. 2013; 4(14): 586- 589.

[25] Bility KM. School violence and adolescent mental health in South Africa: Implications for school health programs. Sociological Practice: A Journal of Clinical and Applied Sociology. 1999; 7(4): 285-303.

[26] Hoberg SM. The crisis generation: peer influence on adolescent substance abuse. Educare. 2003; 32(1 \&2): 240260.

[27] Unger JB. Stressful life events among adolescents in Wuhan China: Association with smoking alcohol use and depressive symptoms. International Journal of Behavioural Medicine. 2001; 5(1): 1-19.

[28] Manyike PC, Chinawa JM, Chinawa AT, Herbert AO, Nwokocha ARC, Odutola O. Correlates for Psychoactive Substance Use among Boarding Secondary School Adolescents in Enugu and Ebonyi State of Nigeria, Nigeria. BMC Pediatr. 2016; 16: 78.

[29] Anyanwu OU, Ibekwe RC, Ojinnaka NC. Pattern of substance abuse among adolescent secondary school students in Abakaliki. Journal of Cogent Medicine 2016; 6(2): 125-132.

[30] Nwana OC. Introduction to educational research. Ibadan: Thomas Nelson. 1990.

[31] King'endo M. Incidence and Extent of Substance Abuse among Secondary School Students in Nairobi Province, Kenya: Implications for Specialized Intervention, Unpublished PhD thesis, Kenyatta University. 2010.

[32] Egbuonu I, Ezechukwu CC, Chukwuka JO, Uwakwe R. Substance Abuse Among Female Senior Secondary School Students In Anambra State South Eastern Nigeria, Nigeria Journal of Clinical Practice. 2013; (7)2: 53-55.

[33] Onifade PO, Somoye EB, Ogunwobi O0, Ogunwali A, Akinhammi TA. A descriptive survey of types, spread and characteristics of substance abuse treatment centres in Nigeria, Substance Abuse Treatment Prevention and Policy. 2011; 6(25).

[34] Agu SA, Nwonkwo BE, Obi TC, Sydney-Agbor N, Mgbenkemdi HE. Effect of Gender and Locality on Alcohol abuse among secondary school students. International Journal of Humanity and Social Sciences. 2013; 2(1): 49-53.

[35] Agu SA, Nwonkwo BE, Obi TC, Sydney-Agbor N, Mgbenkemdi HE. Effect of Gender and Locality on Alcohol abuse among secondary school students. International Journal of Humanity and Social Sciences. 2016; 2(1): 49-53. 
[36] Odunukwe R. Knowledge of the dangers of sexually transmitted infection as a predictor of avoidance of unprotected sexual intercourse. Journal of health psychology. 2016; 6: 336-342.

[37] Branstetter SA, Low S, Furman W. The Influence of Parents and Friends on Adolescent Substance Use: A Multidimensional Approach. J Subst Use. Apr 2011; 16(2): 150-160.

[38] Chukwujekwu, CD. Psychoactive Substance Use among Nigerian Students; Patterns and Sociodemographic Correlates-American Journal of Psychiatry and Neuroscience. 2017; 5(2): 22-25.

[39] Bronfrenbrenner U. The ecology of human development. Cambridge: Harvard Press. 1979.

[40] Ellickson PL, Perlman M, Klein DJ. Explaining racial / ethnic differences in smoking during the transition to adulthood. Addictive Behaviors. 2003; 28: 915-931.

[41] Kobus K. Peers and adolescent smoking. Addiction. 2003; 98(Suppl 1): 37-55.

[42] Becker RN. Determinants of Health Behaviour. American Journal of Health Education. 2000; 25(6): 380-384.

[43] Larson NI, Neumark-Sztainer D, Hannan PJ, Story M. Family meals during adolescence are associated with higher diet quality and healthful meal patterns during young adulthood. J Am Diet Assoc. 2007; 107(9): 1502-10.

[44] Simons-Morton BG, Farhat T. Recent findings on peer group influences on adolescent smoking. Journal of Primary Prevention. 2010; 31: 191-208.

[45] Steinberg L, Monahan KC. Age Differences in Resistance to Peer Influence, Developmental Psychology. 2007; 43(6): 1531-43. 